\title{
ENFERMEDAD DE VON HIPPEL-LINDAU: UNA PRESENTACIÓN ATÍPICA
}

\author{
J.M. ABASCAL JUNQUERA, S. ESQUENA FERNÁNDEZ, R. MARTOS CALVO, \\ C. RAMÍREZ SEVILLA, F. SERRALLACH OREJAS, Y. ID M`HAMMED, \\ E. TRILLA HERRERA, E. MURIO, I. DE TORRES*, J. MOROTE ROBLES
}

Servicio de Urología. *Servicio de Anatomía Patológica. Hospital Universitario Vall d'Hebrón. Barcelona.

Actas Urol Esp. 28 (2) 138-140, 2004

\section{RESUMEN}

ENFERMEDAD DE VON HIPPEL-LINDAU: UNA PRESENTACIÓN ATÍPICA

OBJETIVO: Describir una presentación atípica de la enfermedad de von Hippel-Lindau.

MATERIAL Y MÉTODO: Presentamos la clínica, diagnóstico y tratamiento de las manifestaciones urológicas de esta enfermedad, de índole mayormente neurológica, en un varón joven con antecedentes familiares de la misma.

CONCLUSIONES: Es importante para el urólogo el conocimiento básico de la enfermedad de von Hippel-Lindau porque las manifestaciones genitourinarias de ella son frecuentes, y constituyen una de las causas predominantes de morbi-mortalidad.

PALABRAS CLAVE: Enfermedad de von Hippel-Lindau. Carcinoma de células claras.

\section{ABSTRACT}

\section{VON HIPPEL-LINDAU DISEASE: AN ATYPICAL PRESENTATION}

OBJECTIVE: To describe an atypical presentation of von Hippel-Lindau disease.

MATERIAL AND METHODS: We present the clinical, diagnostic and treatment of the urological signs of this disease, which has overcoat a neurological management, in a young man with familiar history of it.

CONCLUSIONS: The basic knowledge of the von Hippel-Lindau disease is important for the urologist because the urological signs of it, are common and they make up one of the most important causes of morbility and mortality.

KEY WORDS: Von Hippel-Lindau disease. Renal cell carcinoma.

$L^{a}$ a enfermedad de von Hippel-Lindau (VHL) es un trastorno autosómico dominante que se manifiesta por la presencia de hemangioblastomas cerebelosos, angiomas retinianos, quistes pancreáticos, renales y epididimarios, feocromocitomas y carcinoma de células renales. La caracterización genética de este trastorno requiere el estudio de los familiares de los pacientes.

Las lesiones urológicas pueden ser la presentación inicial de la VHL, lo que ofrece al urólogo una oportunidad única para el diagnóstico precoz de la enfermedad y la participación en el cribado de los pacientes con factores de riesgo.

\section{CASO CLÍNICO}

Se trata de un paciente varón de 39 años de edad sin alergias medicamentosas ni hábitos tóxicos conocidos. A los 18 años, a raíz de un cuadro de disminución de la agudeza visual, se le diagnosticó de angiomatosis retiniana bilateral. 
Actualmente presenta una amaurosis residual del ojo izquierdo y estrabismo divergente. En ese momento la TAC cerebral fue normal. A los 38 años sufrió un desprendimiento de retina del ojo derecho que requirió intervención quirúrgica. A raíz de este último cuadro se practicaron nuevas pruebas de cribado de la VHL. La TAC cerebral fue normal y la RMN cráneo-medular evidenció una lesión intramedular quística a nivel de C2$\mathrm{C} 4$, que provocaba un engrosamiento del cordón y otros nódulos en D2-D3 y D11-D12, compatibles con hemangioblastomas extramedulares. La gammagrafía ósea fue negativa y la TAC abdomino-pélvica evidenció una imagen quística a nivel del cuerpo del páncreas; varias lesiones quísticas y una lesión sólida hipervascularizada de $1 \mathrm{~cm}$ de diámetro en riñón derecho y otra de $3,5 \mathrm{~cm}$ en riñón izquierdo compatibles con hipernefromas, además de una adenopatía retroperitoneal adyacente a vena renal izquierda (Fig. 1). La angioTAC objetivó a nivel del riñón derecho varias lesiones quísticas y tumoración sólida en polo inferior de $1,8 \mathrm{~cm}$ y en el polo superior del riñón izquierdo tumoración sólida de $3 \times 3 \mathrm{~cm}$ hipervascularizada y una adenopatía situada por detrás de la vena renal izquierda y algunos quistes pancreáticos (Figs. 2 y 3). Clínicamente el paciente estaba asintomático, siendo la exploración física y analítica normales.

Ante el diagnóstico clínico de tumor renal bilateral y posible adenopatía metastásica se realizó, a través de incisión de Chevron, nefrectomía par-

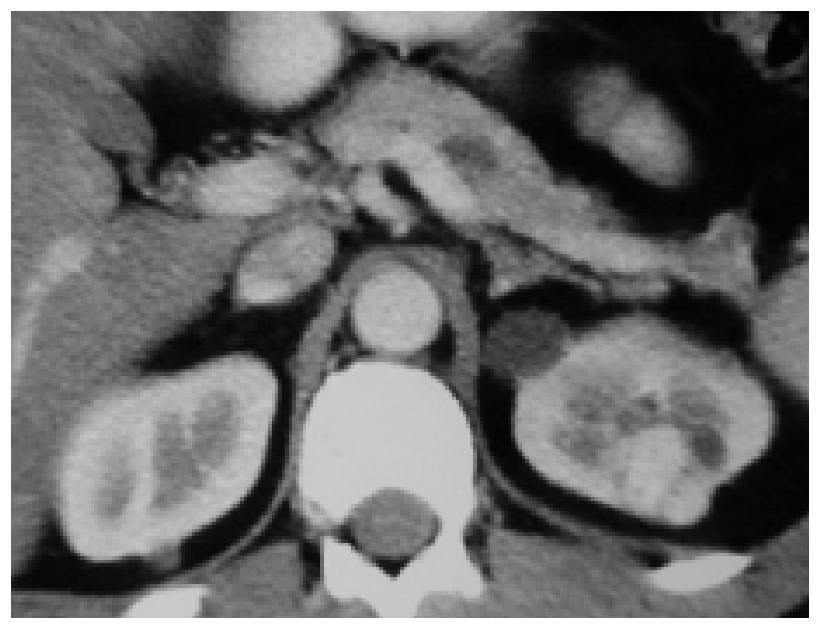

FIGURA 1. TAC abdomino-pélvica: quiste pancreático central. Tumoración exofitica de aprox. $3 \mathrm{~cm}$ en polo superior de riñón izquierdo.

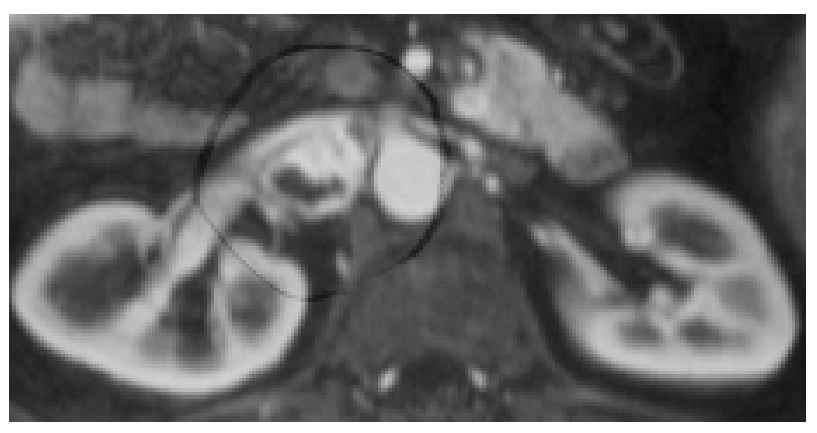

FIGURA 2. Angio-TAC: destaca masa adenopática a nivel del hilio renal izquierdo de aprox. $3 \mathrm{~cm}$, por detrás de la vena renal.

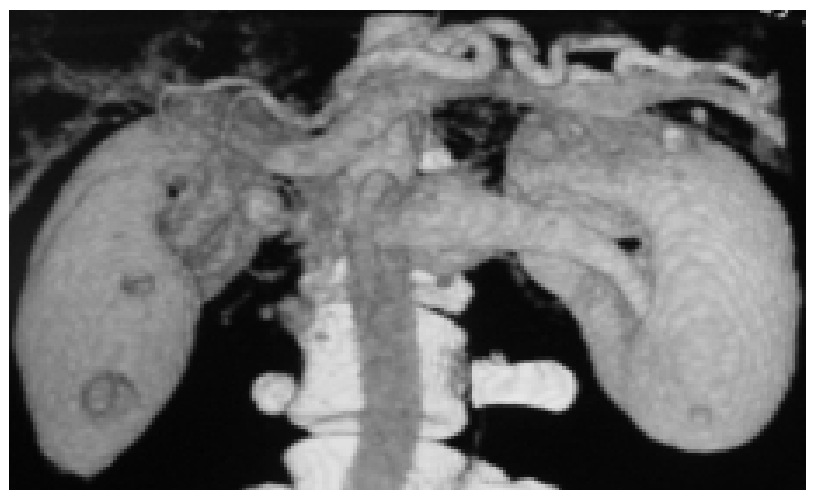

FIGURA 3. Reconstrucción tridimensional previa a la cirugia.

cial derecha y nefrectomía radical izquierda con linfadenectomía periaórtica. En el mismo acto quirúrgico la exploración pancreática demostró múltiples nódulos de pequeño tamaño en la cola y cuerpo realizándose pancreatectomía corporocaudal conservando el bazo.

El diagnóstico anatomopatológico fue de carcinoma de células claras (CCL) en riñón izquierdo (grado nuclear de Fuhrman 2 y estadio pT1), CCL en riñón derecho (grado nuclear III de Fuhrman; parénquima renal de margen quirúrgico sin presencia de nidos neoplásicos), paraganglioma retroperitoneal y tumores múltiples neuroendocrinos de páncreas.

Con buena evolución posterior, el paciente no presenta signos clínicos ni radiológicos de recidiva tumoral al año de seguimiento.

\section{DISCUSIÓN}

La enfermedad de von Hippel-Lindau pertenece a un grupo de síndromes neurocutáneos conocidos como facomatosos (neurofibromatosis o enfermedad de von Recklinghausen, esclerosis 
tuberosa y síndrome encéfalo-trigémino). Estos síndromes son hereditarios de componente autosómico y se caracterizan por la tendencia al desarrollo de lesiones hamartomatosas benignas y malignas en órganos de origen ectodérmico y vísceras abdominales ${ }^{1}$.

Las características más frecuentes y precoces de la VHL son los hemangioblastomas de retina y sistema nervioso central. La afectación de aparato genitourinario en la VHL se limita básicamente a los riñones, glándulas suprarrenales y epidídimos. Estas manifestaciones son con frecuencia precoces, multifocales y bilaterales ${ }^{2}$.

Las lesiones renales pueden ser quistes, adenomas, angiomas y carcinomas de células renales. Los quistes renales son frecuentes y se observan en casi las dos terceras partes de los afectados por la VHL. Su apariencia abarca desde los quistes simples (Bosniak I) hasta quistes complicados (Bosniak IV). El epitelio displásico y claramente maligno que a menudo reviste las paredes del quiste y su potencial maligno suele ser difícil de establecer mediante técnicas de imagen convencionales ${ }^{3}$. La aparición de quistes puede además preceder a los tumores en 5 años ó más ${ }^{4}$. Estas características han llevado a algunos grupos a definir este tipo de quistes como lesiones precursoras de tumores renales sólidos en la $\mathrm{VHL}^{5}$. Las lesiones malignas son en su mayoría adenocarcinomas de células claras que suelen ser multifocales y bilaterales hasta en el $75 \%$ de los casos. De hecho hasta el 50\% de la mortalidad en la VHL se asocia al carcinoma renal ${ }^{6}$. El feocromocitoma adrenal afecta al $10-20 \%$ de pacientes y las lesiones del epidídimo incluyen quistes simples y cistoadenomas papilares.

El tratamiento quirúrgico del carcinoma renal en el contexto de la VHL requiere la extirpación completa de todas las lesiones renales sólidas y quísticas ${ }^{7} \mathrm{y}$ ocasionalmente como en el caso presentado se requieren actuaciones más complejas con diagnósticos inciertos.

\section{REFERENCIAS}

1. UZZO R, NOVICK A.: Enfermedad de von HippelLindau: consideraciones para el urólogo. AUA series 1998, Ed. Castellano, lección 18: 49-54.

2. GLASSBERG K.: Displasia renal y enfermedad quística del riñón. Campdell's in Urology, 6 ${ }^{a}$ edición; 2: 1459-1460

3. CHOYKE PL, GLENN GM, WALTHER MM et al.: Von Hippel-Lindau disease: genetic, clinical and imaging features. Radiology 1995; 194: 629-642.

4. CHOYKE PL, GLENN GM, WALTHER MM et al.: The natural history of renal lesions in VHL disease: a serial CT study in 28 patients. Am $J$ Roentogenol 1992; 159: 1229-1234.

5. SOLOMON D, SCHWARTZ A.: Renal pathology in von Hippel-Lindau disease. Hum Pathol 1988; 19: 1072-1079.

6. MATHER ER, YATES JR, HARRIES R et al.: Clinical features and natural history of von Hippel-Lindau disease. Q J Med 1990; 77: 1151-1163.

7. CHRISTENSON PJ, CRAIG JP, BIBRO MC et al.: Cysts containing renal cell carcinoma in von HippelLindau disease. J Urol 1982; 128: 798-800.

Dr. J.M. Abascal Junquera

Passeig Vall d'Hebron, 119-129

08035 Barcelona

(Trabajo recibido el 29 julio de 2003) 